\title{
CHỈ SỐ HIỆU QUẢ MÔI TRƯờnG (EPI): THỰC TRẠNG VÀ GIẢI PHÁP TÙ GÓC NHİN KINH TẾ TẠI VIẸTT NAM
}

\author{
Trần Thọ Đạt ${ }^{1}$, Đinh Đức Trường ${ }^{1}$
}

Tóm tắt: Bài viết này giới thiệu về chỉ số hiệu quả môi trường (Environmental Performance Index - EPI), thực trạng và diễn biến EPI tại Việt Nam và nhüng lý giải tù góc nhìn kinh tế. Những kết quả nghiên cứu cho thấy trong giai đoạn 2012-2018, Việt Nam đang tụt hạng dần trong thú bậc EPI. Nhũng nguyên nhân được nhận diện gồm (i) mô hình tăng truởng phu thuộc vào tài nguyên gây ô nhiễm môi truò̀ng, (ii) sụ nhập khẩu chất thải và ô nhiễm cùng dòng vốn FDI, và (iii) sự phân công lao động quốc tế và thứ bậc thấp của Việt Nam trong chuỗi giá trị đi kèm với ô nhiễm môi truờng. Bài báo cũng đưa ra nhũng gợi ý chinh sách để cải thiện EPI trong bối cảnh hội nhập kinh tế, đặc biệt nhấn mạnh vào lựa chọn mô hình tăng trưởng và cách thức nhìn nhận giá trị của tài nguyên môi trường với phát triển kinh tế.

Từ khóa: Chỉ số hiệu quả môi trường EPI, tăng trương kinh tế, bảo vệ môi truờng, biến đổi khi hậu, đầu tư trực tiếp nước ngoài, quản lý môi truoòng.

Ban Biên tập nhận bài: 12/08/2019 Ngày phản biện xong: 12/09/2019 Ngày đăng bài: 25/10/2019

\section{Mở đầu}

Quá trình đổi mới tại Việt Nam (1986) đã mang lại nhiều thành tựu về phát triển kinh tế xã hội cho đất nước. Từ một nền kinh tế nông nghiệp lạc hậu với 90\% dân số làm nông nghiệp, Việt Nam đã xây dựng được cơ sở vật chất-kỹ thuật, hạ tầng kinh tế-xã hội từng bước đáp ứng cho sự nghiệp công nghiệp hóa $(\mathrm{CNH})$, hiện đại hóa, tạo ra môi trường thu hút nguồn lực xã hội cho phát triển. Tuy nhiên, mặt trái của sự phát triển là ô nhiễm môi trường ngày càng trở nên trầm trọng hơn. Việt Nam cũng là một trong 5 quốc gia chịu ảnh hưởng nặng nề nhất của biến đổi khí hậu (BĐKH) [1]. Thiệt hại kinh tế do ô nhiễm môi trường được ước tính khoảng 5\% GDP và do BĐKH khoảng 1,5-1,8\% GDP [3, 9]. Ngoài ra, tài nguyên thiên nhiên cũng đang bị cạn kiệt nhanh chóng do quá trình khai thác "vô tội vạ" phục vụ cho tăng trưởng kinh tế. Những vấn đề tài nguyên- môi trường và $\mathrm{BĐKH} \mathrm{đã} \mathrm{trở}$ thành mối đe dọa lớn với sự phát triển bền vững của đất nước trong thế kỷ 21 . Bài viết này có mục tiêu chủ yếu là giới thiệu về chỉ số hiệu quả môi trường (Environmental Performance Index -
$E P I)$, thực trạng EPI tại Việt Nam và những lý giải từ góc nhìn kinh tế cũng như những gợi ý chính sách để cải thiện EPI trong thời gian tới trong bối cảnh $\mathrm{CNH}$ và hội nhập kinh tế.

\section{Chỉ số hiệu quả môi trường EPI - thực} trạng của Việt Nam

Chỉ số hiệu quả môi trường (EPI) là một chỉ số tổng hợp được Trung tâm Chính sách và Luật Môi trường Yale (YCELP) tại Đại học Columbia xây dựng và đề xuất năm 2006 để để đánh giá tính bền vững về môi trường ở các quốc gia [14]. EPI gồm nhiều chỉ số thành phần và chia thành hai nhóm lớn. Nhóm thứ nhất để đo những nỗ lực giảm áp lực lên môi trường về sức khỏe con người, được gọi là nhóm chỉ số sức khỏe môi trường (Environmental Health). Nhóm thứ hai đo việc giảm những mất mát hay suy giảm hệ sinh thái và nguồn tài nguyên thiên nhiên, được đưa vào nhóm chỉ số tính bền vững hệ sinh thái (Ecosystem Vitality). Cho đến tháng 1 năm 2012, 04 báo cáo EPI đã được phát hành - Chỉ số Hiệu quả Môi trường Thí điểm 2006, và Chỉ số hiệu quả Môi trường 2008, 2010, và 2012. Năm 2012, YCELP tiếp tục công bố báo cáo EPI tại Diễn 
đàn Kinh tế thế giới nhằm mục đích xếp hạng (EPI rank) và đánh giá xu hướng (Trend EPI rank) về hiệu quả hoạt động BVMT cho 132 quốc gia, cho phép xác định các quốc gia nào đang cải thiện và quốc gia nào đang suy giảm.

Bảng 1. EPI và các chỉ số thành phần của Việt Nam năm 2012 [14]

\begin{tabular}{lcc}
\hline Cấp độ tổng hộp & Điểm & Thứ hạng \\
\hline Chỉ số hiệu quả môi trường EPI & 50,6 & 79 \\
\hline Sức khỏe môi trường & 51,6 & 91 \\
Không khí (tác động đến sức khỏe con người) & 31 & 123 \\
Sự liên quan của môi trường đến bệnh tật & 66,4 & 77 \\
Nước (tác động đến sức khỏe con người) & 42,5 & 80 \\
\hline Tính bền vững của hệ sinh thái & 50,2 & 62 \\
Nông nghiệp & 47,8 & 80 \\
Không khí (tác động đến hệ sinh thái) & 43,8 & 55 \\
Đa dạng sinh học và môi trường sống & 54,1 & 77 \\
Biến đổi khí hậu & 56,5 & 49 \\
Ngư nghiệp & 19,4 & 82 \\
Rừng & 81,4 & 65 \\
Tài nguyên nước (tác động đến hệ sinh thái) & 37,8 & 47 \\
\hline
\end{tabular}

Theo báo cáo xếp hạng EPI của Yale, Việt Nam có EPI năm 2012 là 50,6 điểm xếp thứ 79/132 quốc gia được xếp hạng, thuộc nhóm nước có năng lực quản lý môi trường trung bình và tương đương với các quốc gia đang phát triển trên thế giới như Chile, Indonesia, Myanmar, Cambodia, Peru Mexico, Venezuela, Honduras và UAE (phân loại theo 5 mức: năng lực rất tốt, năng lực tốt, năng lực trung bình, năng lực kém và năng lực rất kém). Ngoài ra, xếp hạng xu hướng cải thiện năng lực quản lý môi trường, Việt Nam đạt 4,2 điểm và xếp hạng 73/132 quốc gia, thuộc nhóm các quốc gia có những cải thiện nhỏ về năng lực (phân loại theo 5 mức: cải thiện rất tốt, cải thiện tốt, cải thiện nhỏ, suy giảm tương đối, suy giảm rất nhiều) [14].

Trong các chỉ số thành phần, nhóm chỉ thị về chất lượng không khí ảnh hưởng đến sức khỏe: Việt Nam xếp vào nhóm 10 nước ô nhiễm nhất (hạng 123/132), tương đương với một số quốc gia châu Á như Trung Quốc, Ấn Độ, Pakistan, Nêpan và Bangladesh $[5,13]$.
Trong khu vực ASEAN Việt Nam hiện xếp thứ 7/11 quốc gia, cùng nhóm với Thái Lan, Indonesia, Đông Timo và Myanmar. Xếp hạng cao nhất trong khu vực là Sigapore (hạng 49) và thấp nhất là Lào (hạng 153). Các quốc gia Châu Âu và Scandinavia chiếm các vị trí cao nhất trên bảng xếp hạng: Thụy Sỹ hạng nhất, sau đó đến Pháp (hạng 2), Đan Mạch (hạng 3), Manta (hạng 4), Thụy Điển (hạng 5) [8].

Về cơ bản, EPI của Việt Nam nằm ở dưới mức trung bình của thế giới và xu hướng xếp hạng ngày càng đi xuống. Nếu như năm 2102 Việt Nam xếp thứ 79/132 thì năm 2016 tụt xuống thứ 131/178 và 2018 xếp thứ 132/180 quốc gia. Trong đó, năm 2018, chỉ số sức khỏe môi trường Việt Nam xếp thứ 129/180 và chỉ số sức khỏe hệ sinh thái xếp thứ 124/180 quốc gia. Về điểm, Việt Nam đạt 46,96 điểm EPI năm 2018 so với 50.6 năm 2012. Như vậy, EPI cho thấy Việt Nam ngày càng tụt hậu về môi trường so với chính mình và so với các quốc gia khác trên thế giới. 


\section{BÀI BÁO KHOA HỌC}

Bảng 2. EPI và xếp hạng một số quốc gia OECD, NICs và lân cận Việt Nam [6, 14]

\begin{tabular}{lccc}
\hline & $\begin{array}{c}\text { GPP/nguời theo PPP } \\
\text { 2017 (USD) }\end{array}$ & EPI (2018) & $\begin{array}{c}\text { Xếp hạng EPI } \\
\mathbf{2 0 1 8}\end{array}$ \\
\hline Các quốc gia OECD & \\
Hoa Kỳ & 59.495 & 71.19 & 27 \\
Canada & 48.141 & 72.18 & 25 \\
Đức & 50.206 & 78.37 & 13 \\
Pháp & 43.550 & 83.95 & 2 \\
Anh & 43.620 & 79.89 & 6 \\
Nhật Bản & 42.695 & 74.699 & 20 \\
Hàn Quốc & 39.387 & 62.30 & 60 \\
Italia & 37.970 & 76.96 & 16 \\
\hline \multicolumn{4}{c}{ Các quốc gia công nghiệp mới (NICs) } \\
\hline Brazil & 15.500 & 60.70 & \\
Mexico & 19.480 & 59.69 & 72 \\
Malaysia & 28.871 & 59.22 & 75 \\
Nam Phi & 13.403 & 44.73 & 142 \\
Án Độ & 7.174 & 30.57 & 177 \\
\hline & Một số quốc gia khác & \\
\hline Trung Quốc & 16.624 & 50.74 & 120 \\
Thái Lan & 17.786 & 49.88 & 121 \\
Indonesia & 12.378 & 46.92 & 133 \\
Singapore & 90.531 & 64.23 & 49 \\
Việt Nam & 6.876 & 46.96 & 132 \\
\hline
\end{tabular}

3. Chỉ số EPI với quá trình công nghiệp hóa và phát triển kinh tế tại Việt Nam

Cho đến nay, đã có nhiều nghiên cứu chỉ ra mối quan hệ ngược chiều có ý nghĩa giữa tăng trưởng kinh tế và sự suy giảm tài nguyên và môi trường ở Việt Nam, và rằng mức độ suy giảm ngày càng trầm trọng hơn. Bài viết này phân tích và lý giải về xu hướng suy giảm của chỉ số EPI từ góc độ kinh tế của đất nước.

\subsection{Mô hình tăng trưởng phụ thuộc vào tài} nguyên thiên nhiên và gây ô nhiễm môi trường

Lý thuyết và các bằng chứng thực nghiệm cho thấy có 4 nhân tố căn bản của tăng trưởng kinh tế gồm vốn vật chất, vốn con người, tài nguyên thiên nhiên và khoa học công nghệ. Các quốc gia khác nhau sẽ có sự lựa chọn chiến lược khác nhau việc sử dụng các nhóm nhân tố tăng trưởng kinh tế và tăng năng suất.

Trong một thời gian dài, nếu nhìn vào cấu trúc kinh tế, có thể thấy việc khai thác tài nguyên chiếm một tỷ trọng rất lớn trong nguồn thu ngân sách và góp phần tăng trưởng kinh tế tại Việt Nam. Nói cách khác, nền kinh tế Việt Nam thâm dụng tài nguyên thiên nhiên (natural resource intensive economy). Thực ra, việc khai thác tài nguyên để tăng trưởng không có gì lạ trên thế giới; nhiều quốc gia đã dựa vào tài nguyên để tạo ra đòn bẩy tăng trưởng trong những giai đoạn đầu của công nghiệp hóa, với họ tài nguyên thiên nhiên là nguồn lực tạo ra sự kích thích tăng trưởng ban đầu và tích lũy vốn để tái đầu tư cho những nguồn lực tăng trưởng khác (công nghệ, vốn con người). Tuy nhiên, Việt Nam lại coi khai thác tài nguyên là một phương thức để tăng trưởng chủ đạo trong khi quá chậm trong chuyển sang các bước cao hơn trong các giai đoạn của quá trình $\mathrm{CNH}$.

Mô hình tăng trưởng dựa vào khai thác tài nguyên của Việt Nam hiện quá lạc hậu so với các nước trong khu vực và trên thế giới. Cụ thể, các nước ASEAN như Indonesia, Thái Lan và Malaysia đã chuyển sang giai đoạn phát triển công nghiệp phụ trợ, làm chủ một phần công nghệ, có sự hướng dẫn của nước ngoài, Trung Quốc thậm chí đã nắm vững và quản lý công nghệ, sản xuất các hàng hóa với chất lượng cao 
như xe hơi, điện thoại, công nghệ ICT, năng lượng tái tạo thì Việt Nam vẫn chủ yếu dựa vào công nghiệp chế tạo giản đơn dưới sự hướng dẫn của nước ngoài và các ngành khai khoáng. Mô hình này chỉ hơn các nước nghèo ở Châu Phi với sản xuất nông nghiệp đơn giản và phụ thuộc vào viện trợ của nước ngoài.

\section{Các giai đoạn công nghiệp hóa}

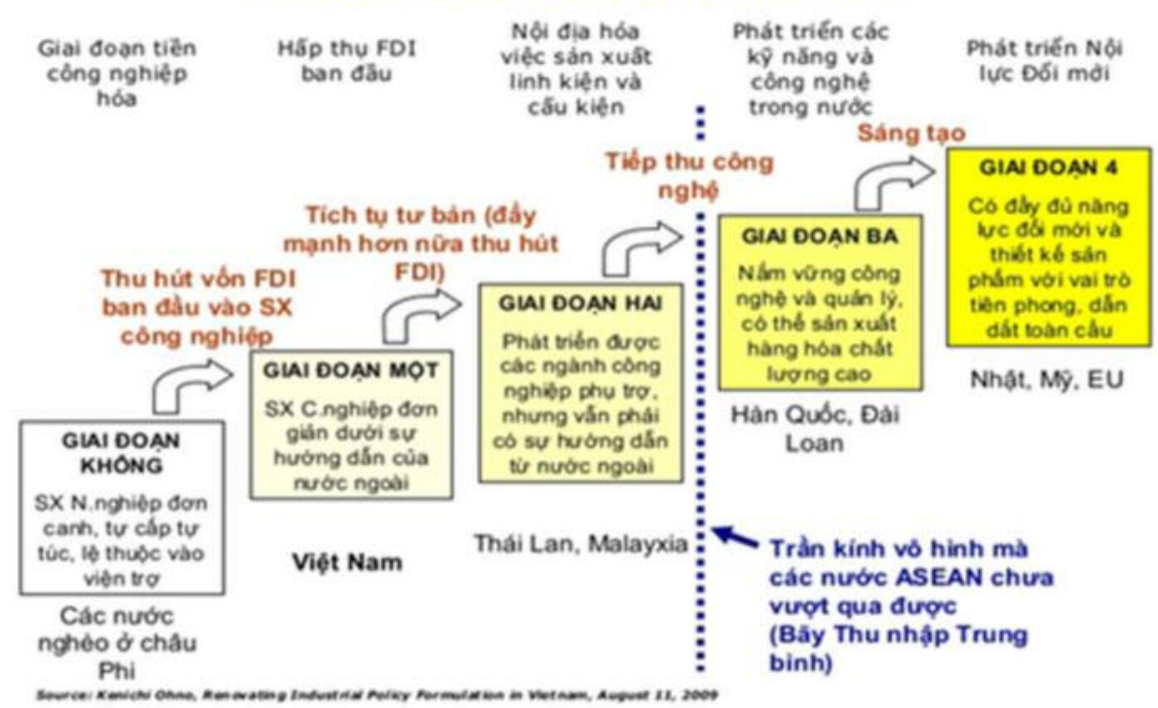

Hình 1. Các giai đoạn công nghiệp hóa của các quốc gia [10]

Hiện nay nước ta là một trong những quốc gia có cường độ tiêu thụ năng lượng cao nhất thế giới (năng lượng cần thiết tiêu thụ để tạo ra một đơn vị GDP). So sánh với 10 nước (Nhật Bản, Mỹ, Singapore, Hàn Quốc, Philippines, Malaysia, Indonesia, Thái Lan, Trung Quốc và Việt Nam), Việt Nam đứng cao nhất. Việt Nam chỉ thấp hơn Trung Quốc và cao gấp sáu lần so với Nhật Bản, Mỹ (bốn lần), Singapore (3,5 lần), Hàn Quốc (2,6 lần), Philippines (2 lần),
Malaysia (1,6 lần)... Điều này cho thấy một khoảng cách khá xa về trình độ khoa học kỹ thuật, hiện trạng công nghệ áp dụng cho sản xuất của Việt Nam so với nhiều nước phát triển và đang phát triển. Nguy hiểm hơn đó là xu hướng đầu tư và phát triển những ngành công nghiệp khai thác nhiều tài nguyên, tiêu dùng năng lượng lớn nhưng lại không mang lại hiệu quả kinh tế cao cho đất nước.

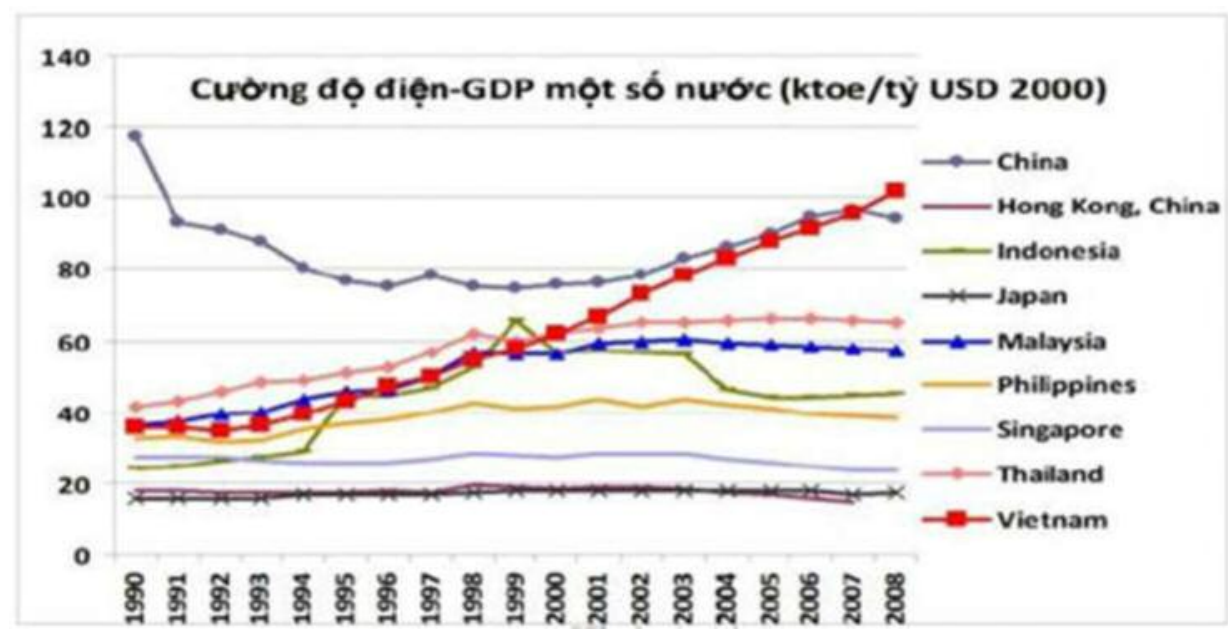

Hình 2. Cuờng độ tiêu thu điện-GDP một số quốc gia [11] 


\section{2 Đầu tư trục tiếp nước ngoài (FDI) và ô nhiễm môi trường sinh thái}

Đầu tư trực tiếp nước ngoài là một trụ cột tăng trưởng kinh tế của Việt Nam. Sau 30 năm Luật Đầu tư trực tiếp nước ngoài ra đời, Việt Nam đã thu hút được hơn 23.000 dự án FDI với tổng vốn đăng ký trên 300 tỷ USD, trong đó, số vốn thực hiện nước đạt khoảng 161 tỷ USD. Trong 3 thập niên qua, FDI đã góp phần bổ sung nguồn vốn đầu tư phát triển, giải quyết việc làm, tăng thu ngân sách, thúc đẩy chuyển giao công nghệ và tiến trình hội nhập quốc tế của Việt Nam. Đáng chú ý, hiện khu vực FDI chiếm đến $72 \%$ kim ngạch xuất khẩu và tạo việc làm cho 2 triệu lao động, đóng góp vào 40\% tăng GDP [12].

Tuy nhiên, mặt trái của FDI là ô nhiễm và suy thoái môi trường. Mối quan hệ giữa FDI và môi trường được thể hiện qua "Định đề thiên đường ô nhiễm" (Pollution Haven Hypothesis) được phát triển từ thập niên 1980. Theo đó, các quốc gia công nghiệp hóa sẽ thành lập các công ty, nhà máy, trụ sở tại các nước đang phát triển để tận dụng nguồn tài nguyên thiên nhiên giá rẻ cùng các qui định kém chặt chẽ hơn về môi trường để cắt giảm chi phí so với chi phí tương ứng tại nước mẹ. Từ đó, dòng đầu tư có xu hướng chuyển dịch từ các quốc gia có tiêu chuẩn môi trường khắt khe sang các quốc gia có tiêu chuẩn và hệ thống giám sát lỏng lẻo hơn [10].

Các bằng chứng thực nghiệm đã chứng minh định đề này khá đúng tại Việt Nam, khi FDI tăng lên thì chất lượng môi trường giảm xuống. Nghiên cứu của Trường Đại học Kinh tế quốc dân (2016) đã cho thấy có sự gia tăng đáng kể chất gây ô nhiễm cùng với sự gia tăng của FDI tại Việt Nam, cụ thể khi FDI tăng lên $1 \%$ thì lượng khí thải ô nhiễm tăng 2,7\%, nước thải tăng $1.6 \%$ và năng lượng tiêu thụ tăng 1,5\%. Cũng theo nghiên cứu này, có tới $70 \%$ doanh nghiệp FDI cho biết đầu tư vào Việt Nam sẽ tiết kiệm chi phí về môi trường so với chính quốc. Thông thường, tại các nước này chi phí xử lý nước thải các ngành dệt nhuộm, sắt thép, giấy, bột ngọt... là rất lớn, việc quản lý, giám sát xả thải rất khó, đòi hỏi trình độ kỹ thuật cao. Vì thế, khi đầu tư tại Việt Nam sẽ tiết kiệm chi phí 30-50\% so với tại nước mẹ. Nhiều địa phương do chạy theo thành tích thu hút FDI nhưng hiệu quả kinh tế thấp, gây ô nhiễm nghiêm trọng, không bền vững.

Đáng nói, đến năm 2013, chỉ có 5\% doanh nghiệp FDI đầu tư vào Việt Nam có công nghệ cao, $80 \%$ có công nghệ trung bình, còn lại $14 \%$ là sử dụng công nghệ thấp. Điều này hoàn toàn trái ngược kỳ vọng cũng như tuyên bố đưa các công nghệ, ứng dụng tiên tiến vào sản xuất tại Việt Nam. Hiện có đến $80 \%$ khu công nghiệp vi phạm các quy định về môi trường; $70 \%$ doanh nghiệp FDI xả thải vượt quy chuẩn, $23 \%$ trong số đó xả chất thải vượt quy chuẩn cho phép 5-12 lần [12].

Điển hình năm 2008, Công ty Vedan Việt Nam xả thải, gây ô nhiễm trên sông Thị Vải (Đồng Nai). Với việc xả chui $100.000 \mathrm{~m}^{3}$ nước thải độc ra sông mỗi tháng, bán kính ô nhiễm rộng tới $10 \mathrm{~km}$ dọc bờ sông Thị Vải, Vedan đã làm thiệt hại gần 2.700ha nuôi trồng thủy sản của Đồng Nai, thành phố Hồ Chí Minh và Bà Rịa Vũng Tàu. Mới đây nhất, Công ty TNHH Gang thép Hưng Nghiệp Formosa Hà Tĩnh thuộc Đài Loan đã xả thải hủy hoại nghiêm trọng môi trường biển 4 tỉnh miền Trung (Hà Tĩnh, Quảng Bình, Quảng Trị và Thừa Thiên - Huế). Bên cạnh đó, còn nhiều doanh nghiệp FDI liệt kê vào danh sách đen các cơ sở gây ô nhiễm môi trường như: công ty TNHH Huyndai- Vinasin (Khánh Hoà); công ty TNHH Miwon Việt Nam; công ty Tung Kuang; công ty TNHH Mei SHeng Textiles Việt Nam (Trung Quốc), Công ty Chia Chen (Ninh Bình).

\subsection{Vị trí thấp của Việt Nam trong nấc thang} chuỗi giá trị sản xuất toàn cầu

Một trong những nguyên nhân ô nhiễm môi trường của Việt Nam xuất phát từ đặc trưng tham gia công đoạn gia công trong chuỗi giá trị toàn cầu. Gia công là công đoạn có giá trị gia tăng thấp nhất, chiếm dụng lao động trình độ thấp và tiêu tốn nhiều tài nguyên, năng lượng, gây ô nhiễm môi trường. Thực tế cho thấy, nền kinh tế 
nước ta được duy trì quá lâu trong đẳng cấp "giá trị gia tăng thấp”. Hội nhập kinh tế không chỉ là những con số xuất khẩu hay nhập khẩu tính bằng tiền. Điều quan trọng hơn là phải tham gia được vào chuỗi giá trị gia tăng toàn cầu để mở rộng thị trường. Và điều quan trọng nhất là từ vị trí ban đầu, chúng ta phải vươn lên được những vị trí có giá trị gia tăng cao hơn. Khi nhảy lên các bước cao hơn trong chuỗi giá trị (thiết kế, marketing, phân phối, hậu mãi, ý tưởng R\&D), chúng ta vừa bảo vệ được môi trường do những mắt xích này thâm dụng tri thức, năng lực khoa học công nghệ chứ không tiêu thụ tài nguyên như mắt xích gia công, chế tạo hiện tại của Việt Nam, đồng thời góp phần gia tăng phần giá trị kinh tế cho đất nước.

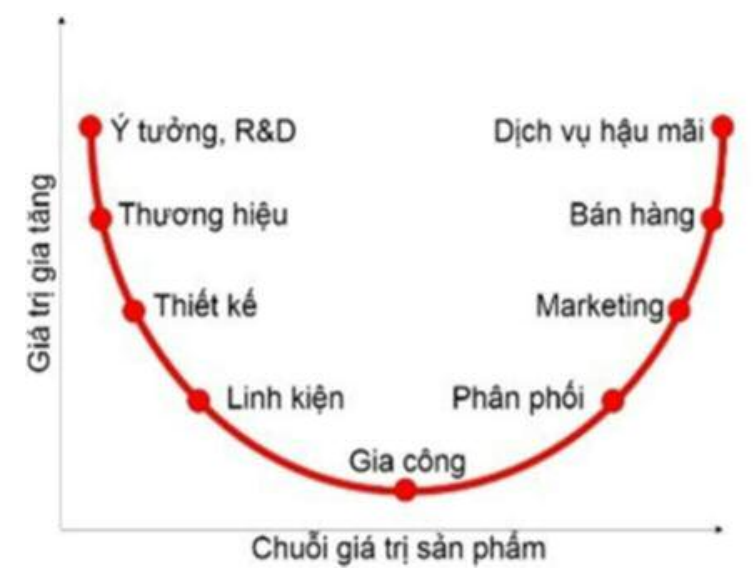

Hình 3. Giá trị gia tăng trong các công đoạn của chuối giá trị [13]

Hiện tại, trình độ công nghệ của nền kinh tế, trong đó có ngành công nghiệp ở Việt Nam còn rất thấp. Ví dụ, trong ngành cơ khí, thiết bị lạc hậu tới 4 thập kỷ so với mặt bằng thế giới. Công nghệ trong ngành sử dụng để sản xuất công cụ, hàng tiêu dùng, máy động học...hầu hết đều ra đời từ trước những năm 1980 và $30 \%$ có tuổi thọ hơn nửa thế kỷ. Tỷ trọng doanh nghiệp có công nghệ cao của Việt Nam mới đạt khoảng 20,6\%, thấp xa so với mức $29,1 \%$ của Philippines, $29,7 \%$ của Indonesia, $30,8 \%$ của Thái lan, $51,1 \%$ của Malaysia, $73 \%$ của Singapore. Với mô hình này, rất khó có thể tạo ra tác động lan tỏa tích cực từ khu vực FDI. Chính vì vậy, các biện pháp chính sách và nỗ lực nhằm tạo ra môi trường kinh doanh thuận lợi, chi phí thấp cho các doanh nghiệp, đặc biệt là doanh nghiệp FDI, tuy cần thiết nhưng vẫn không đủ để thúc đẩy tác động lan toả từ FDI đến việc nâng cao năng suất lao động và hiệu quả đóng góp của TFP vào tăng trưởng [10].

4. Một số hàm ý chính sách góp phần tăng trưởng kinh tế và cải thiện EPI tại Việt Nam trong bối cảnh CNH và hội nhập kinh tế

Hiện nay, các quốc gia trên thế giới được xếp hạng EPI theo 4 nhóm chính là những nước có EPI ở mức cao (top 50), các nước có EPI ở mức trung bình (từ 50-100), các nước có EPI thấp (100-150) và các nước yếu kém về EPI (từ 150 tới 180). Năm 2018, Việt Nam xếp hạng 132 vê EPI tức là nhóm thấp và gần với yếu kém của thế giới, với xu hướng ngày càng tụt hậu trong bảng xếp hạng.

Trong trung và dài hạn, dù cải thiện chất lượng môi trường, rất khó để Việt Nam chen chân vào nhóm top 50 EPI vì nhóm này chủ yếu là những quốc gia có nền kinh tế rất phát triển, có nguồn lực xã hội để đầu tư bảo vệ môi trường. Vì vậy mục tiêu thực tế của Việt Nam là đạt EPI ở mức trung bình khá như các quốc gia NICs tiên tiến. Đó là Brazil (hạng 69), Mexico (hạng 72) và Malaysia (hạng 75) của EPI. Đặc điểm chung của các quốc gia này là có mức $\mathrm{GDP} /$ người tính theo PPP trong khoảng từ 15-28 ngàn USD/năm hiện tại. Đây là mức Việt Nam có thể phấn đấu đạt được.

\subsection{Thay đổi mô hình phát triển kinh tế theo hướng bền vũng}

Như đã trình bày, mô hình phát triển kinh tế của Việt Nam thâm dụng tài nguyên thiên nhiên, gây ô nhiễm môi trường, chiếm giữ những mắt xích thấp nhất trong chuỗi giá trị sản phẩm toàn cầu. Đây là mô hình lạc hậu, không hiệu quả và không bền vững. Thực tế cho thấy nhiều quốc gia đã gặp phải "Lời nguyền tài nguyên" và không thoát khỏi sự lạc hậu sau khi tài nguyên thiên nhiên dần cạn kiệt, ô nhiễm gia tăng và không có những nguồn lực tăng trưởng thay thế. Nếu không thận trọng và có chiến lược đúng đắn, Việt Nam có thể đi theo vết xe đổ của những 
quốc gia này.

Vì vậy, sự lựa chọn thông minh của Việt Nam là từ bỏ mô hình tăng trưởng dựa vào tận khai tài nguyên mà chuyển sang mô hình tăng trưởng xanh, phát triển nguồn nhân lực chất lượng cao và trình độ khoa học công nghệ. Đầu tư vào con người và công nghệ là chiến lược được nhiều quốc gia đã và đang phát triển sử dụng. Nó vừa xây dựng nền tảng và nguồn lực tăng trưởng bền vững lâu dài cho các quốc gia, vừa góp phần thay đổi cấu trúc nền kinh tế sang hướng hiện đại, giảm bớt sự phụ thuộc vào tài nguyên thiên nhiên, cải thiện chất lượng môi trường, giảm ô nhiễm và gia tăng phúc lợi xã hội.

4.2 Thu hút FDI sạch và chuyển dịch vị trí của Việt Nam trong chuỗi giá trị theo hướng bảo vệ môi truờng

FDI là một trụ cột của tăng trưởng kinh tế nhưng lại gây ô nhiễm môi trường tại nước ta. Trong những năm tới đây, FDI vẫn sẽ tiếp tục tăng lên cùng quá trình hội nhập kinh tế quốc tế của Việt Nam. Tuy nhiên, vấn đề là làm sao để dòng FDI mang lại sự phát triển bền vững, tăng hiệu quả kinh tế nhưng không gây ra những tác động tiêu cực tới môi trường.

Như đã phân tích, vấn đề hiện nay của Việt Nam là khó thu hút được dòng FDI sạch. Thái Lan, Malaysia và Trung Quốc hiện đã thu hút được nhiều dự án FDI trong các lĩnh vực sạch như năng lượng tái tạo, ICT, giáo dục, công nghệ sinh học, dịch vụ. Vấn đề mấu chốt là Việt Nam chưa phát triển những ngành công nghiệp hỗ trợ vốn là nền tảng của các ngành công nghiệp sạch [7].

Vì vậy, muốn thay đổi cấu trúc FDI theo hướng thu hút các ngành sạch hơn, không còn cách nào khác là phải phát triển công nghiệp phụ trợ, song song với việc loại trừ dần những ngành FDI 'bẩn' như sắt thép, hóa chất, khai khoáng, dệt nhuộm, giấy. Bên cạnh việc lồng ghép những yêu cầu về qui trình và tiêu chuẩn quản lý môi trường trong việc xét duyệt và lựa chọn dự án FDI, Luật Đầu tư trực tiếp nước ngoài nên bổ sung các chính sách khuyến khích các ngành sạch, thân thiện môi trường.
Chính sách xây dựng ngành công nghiệp hỗ trợ cũng cần xuất phát từ định hướng thu hút FDI. Trong đó, Chính phủ và doanh nghiệp nội địa cần phải tiếp cận nhu cầu của doanh nghiệp FDI, chất lượng và sản phẩm mà họ yêu cầu doanh nghiệp nội địa. Điều này đỏi hỏi cơ quan quản lý phải tạo hành lang pháp lý, định hướng xu hướng và lộ trình phát triển, minh bạch thông tin, tiêu chuẩn để doanh nghiệp phấn đấu đạt được.

\subsection{Tận dụng quá trình hội nhập thwơng mại quốc tế để bảo vệ môi trường}

Thương mại là một trong những khâu quan trọng của tái sản xuất nền kinh tế - xã hội. Nó không những là cầu nối giữa tiêu dùng với sản xuất, mà còn có tác dụng định hướng tiêu dùng thân thiện hơn với môi trường và bảo đảm phát triển bền vững [6].

Thương mại có một vai trò quan trọng trong phát triển kinh tế tại Việt Nam. Năm 2017 tổng kinh ngạch xuất nhập khẩu lên tới gần 400 tỷ USD tức là gấp rưỡi qui mô của GDP. Việt Nam đã ký kết hơn 17 Hiệp định thương mại tự do và ngày càng hội nhập nhiều hơn vào kinh tế thế giới nên thương mại sẽ tiếp tục tăng trưởng trong tương lai gần.

Tuân thủ các qui định về môi trường trong thương mại là một thách thức nhưng cũng mang lại cơ hội cho Việt Nam để cải thiện chất lượng môi trường. Hiện nay, các tiêu chuẩn môi trường đối với hàng hóa nhập khẩu tại các nước phát triển là bắt buộc và rất chặt chẽ. Những quốc gia này có đủ phương tiện, nguồn lực và chế tài để giám sát và xử lý các hàng hóa nhập khẩu không tuân thủ các tiêu chuẩn môi trường. Áp lực của thị trường tiêu thụ, thị hiếu lựa chọn tiêu dùng các sản phẩm xanh, an toàn và rủi ro kinh tế từ việc không tuân thủ các qui định môi trường buộc các doanh nghiệp xuất khẩu Việt Nam phải chuyển mình theo hướng thân thiện hơn, trong đó phải bảo vệ môi trường để đáp ứng các đòi hỏi của thị trường nhập khẩu hàng hóa.

4.4 Tăng cường nhũng khía cạnh kinh tế trong quản lý tài nguyên và môi truò̀ng

Cải thiện hiệu quả quản lý tài nguyên môi 
trường là điểm quan trọng để cải thiện chất lượng và thứ bậc của EPI. Vì vậy, trong công tác quản lý sử dụng tài nguyên và môi trường, cần lồng ghép một số nguyên tắc từ góc độ kinh tế.

Thứ nhất, phải xem môi trường là một loại tài sản của nền kinh tế, tài sản môi trường cung cấp hàng hóa dịch vụ cho tăng trưởng kinh tế (cung cấp không gian, tài nguyên, chứa đựng chất thải), đồng thời cũng bị khấu hao nếu không biết quản lý khai thác sử dụng hợp lý. Với góc nhìn kinh tế, tài sản môi trường là có hạn, việc sử dụng có tính chi phí cơ hội nên phải sử dụng tối ưu (mang lại lợi ích lớn nhất cho cộng đồng và xã hội).

Thứ hai, do môi trường là tài sản nên phải lượng giá được giá trị của tài sản môi trường phục vụ cho các phương án quản lý sử dụng. Do có chi phí cơ hội của việc tiêu dùng tài nguyên và môi trường nên việc lượng giá là cơ sở của việc tính toán lợi ích - chi phí của các phương án sử dụng khác nhau. Từ đó lựa chọn được phương án tối ưu nhất. Lượng giá cũng cho phép lựa chọn các giải pháp phát triển kinh tế, có lồng ghép tính toán đến những chi phí môi trường, vì vậy quyết định phát triển đưa ra sẽ toàn diện hơn.

Thứ ba, chất lượng môi trường trong nền kinh tế thị trường là một loại hàng hóa, có tính chất công cộng, mang lại lợi ích cho nhiều người. Hàng hóa môi trường (hay cải thiện chất lượng môi trường- EPI) là một quá trình đòi hỏi sự đầu tư nguồn lực của xã hội (nhân lực, con người, tài chính). Vì vậy, cần phải huy động được nguồn lực của xã hội cho bảo vệ môi trường, đặc biệt là nguồn tài chính. Hiện nay theo Luật Ngân sách, chi tiêu cho bảo vệ môi trường mới chỉ chiếm $1 \%$ tổng chi ngân sách hàng năm. Để có thể cải thiện tốt hơn chất lượng môi trường góp phần cải thiện EPI cần phải đầu tư và chi tiêu thêm nhiều hơn nữa. Bên cạnh việc gia tăng tỷ lệ chi tiêu ngân sách cho môi trường, cũng cần xây dựng các cơ chế khuyến khích sự tham gia của khối tư nhân, doanh nghiệp, đặc biệt là cơ chế hợp tác công tư (PPP) để thu hút thêm nguồn lực xã hội cho bảo vệ môi trường.

\section{Kết luận}

Chỉ số EPI là một chỉ số tổng hợp phản ánh mức độ bền vững về môi trường cũng như hiệu quả môi trường của một quốc gia. Đây là một chỉ số có tính đa chiều gồm có nhiều thành phần cấu thành, bao hàm nhiều khía cạnh của phát triển. Việc cải thiện chỉ số của một quốc gia không phải là vấn đề kỹ thuật mà là vấn đề quản lý, gắn với mô hình tăng trưởng, chuyển đổi cấu trúc nền kinh tế, liên quan đến các khía cạnh quan trọng của nền kinh tế như thương mại, đầu tư, chuỗi giá trị, đô thị hóa và công nghiệp hóa.

Cải thiện EPI là nhu cầu tất yếu để hướng tới sự phát triển bền vững, hài hòa cân đối giữa kinh tế, xã hội và môi trường. Mấu chốt là việc chuyển đổi mô hình phát triển kinh tế lạc hậu của đất nước, tận dụng ưu thế của cuộc $\mathrm{CMCN} 4.0$ để bước lên các mắt xích cao hơn trong chuỗi giá trị, xây dựng một cấu trúc kinh tế chuyển đổi từ tài nguyên sang thâm dụng nguồn nhân lực chất lượng cao, dựa trên khoa học và công nghệ. Chỉ có như vậy mới cải thiện tận gốc các vấn đề môi trường và mang lại hiệu quả kinh tế cao cho đất nước. Ngoài ra, cũng cần tận dụng quá trình hội nhập kinh tế quốc tế để làm xanh hóa các dòng FDI, xanh hóa sản xuất và tiêu dùng theo qui chuẩn môi trường của thế giới, thay đổi lối sống của người dân theo hướng thân thiện môi trường. Đó là sự lựa chọn của Việt Nam chứ không phải bất khả thi. Và điều này cần tầm nhìn, định hướng phát triển, hệ thống chính sách mạnh mẽ, sáng tạo cũng như phát huy sự tham gia của toàn xã hội để hướng tới sự phát triển bền vững.

Lời cảm ơn: Bài viết này được hỗ trọ̆ chuyên môn và tu liệu tù đề tài khoa học "Nghiên cưu lương giá thiệt hại kinh tế do các hiện tuợng khi tương thuỷ văn cực đoan gây ra trong bối cảnh biến đổi khi hậu và đề xuất các giải pháp quản lý rủi ro cho các tỉnh ven biển miền Trung Việt Nam”. Mã số: BĐKH.22/16-20. Co quan chủ trì: Trường Đại học Kinh tế quốc dân. 


\title{
BÀI BÁO KHOA HỌC
}

\section{Tài liệu tham khảo}

1. Bộ Kế hoạch và Đầu tư và Ngân hàng Thế giới (2016), Báo cáo Việt Nam 2035: Huớng tới Thịnh vuợng, Sáng tạo, Công bằng và Dân chủ, Việt Nam.

2. Climate Position (2016), India's Climate Debt is on track for something big, http://climatepositions.com/indias-climate-debt-is-on-track-for-something-big/.

3. DARA International (2012), Climate Vulnerability Monitor: Findings and Observations. Mendelsohn, R., (2009), Climate Change and Economic Growth, Working Paper No. 60, The World Bank.

4. Đinh Đức Trường (2015), Quản lý môi trương tại các doanh nghiệp đầu tư nước ngoài (FDI) tại Việt Nam. Tạp chí Khoa học ĐHQGHN, 31 (5), 46-55.

5. Institute For Health Metrics And Evaluation (2017), Global Health Data Exchange Database. Retrieved From Http://Ghdx.Healthdata.Org/

6. International Monetary Fund (2018), World Economic Outlook Database.

7. Nguyễn Tuân (2016), Nếu không có DN FDI, ngành công nghiệp phụ trợ của Việt Nam rất khó phát triển, https://infonet.vn/neu-khong-co-dn-fdi-nganh-cong-nghiep-phu-tro-cua-viet-nam-ratkho-phat-trien-post202350.info

8. Tổng Cục Thống kê (2013), Nghiên cứu ưng dụng tính chỉ số bền vũng môi truờng áp dụng cho Việt Nam, Đề tài NCKH cấp Bộ, Mã số: 2.1.7-B12-13.

9. Tổng Cục Thống kê các năm, Số liệu về tăng truởng kinh tế của Việt Nam.

10. Trần Đình Thiên (2012), Nhũng vấn đề của nền kinh tế duy trì quá lâu mô hình tăng truởng dựa vào khai thác tài nguyên và sản xuất gia công lắp ráp. Báo cáo phân tích chính sách, http://nature.org.vn/vn/wp-content/uploads/2014/07/TS.-Tran-Dinh-Thien.pdf.

11. Trần Đình Tuấn (2016), Tăng trương kinh tế Việt Nam sau 10 năm gia nhập WTO, Tạp chí Tài chính kỳ 2 tháng 4/2016.

12. Trường Đại học Kinh tế quốc dân (2016), Anh hương của đầu tư trục tiếp nước ngoài tới môi trương sinh thái tại Việt Nam, Đề tài KHCN cấp Bộ, Bộ Giáo dục và Đào tạo.

13. UNESCAP (2012), Green Growth, Resources and Resilience: Environmentalsustainability in Asia And The Pacific. United Nations and Asian Development Bank Publication, Truy Cập Từ: Http://Www.Unep.Org/Dewa/Portals/67/Pdf/ G2R2_Web.Pdf.

14. Yale Center for Environmental Law and Policy (2012-2018), Center for International Earth Science Information Network at Columbia University, Environmental Performance Index.

\section{ENVIRONMENTAL PERFORMANCE INDEX (EPI): STATUS AND SOLUTIONS FROM ECONOMIC PERSPECTIVES IN VIETNAM}

Tran Tho Dat ${ }^{1}$ and Dinh Duc Truong ${ }^{1}$

${ }^{1}$ The National Economics University, Hanoi

\begin{abstract}
This article introduces the environmental performance index (EPI), the situation and EPI changes in Vietnam and the explanations from the economic perspective. The research results show that in the period of 2012-2018, Vietnam is gradually falling in the EPI hierarchy. Identified causes include: (i) a resource-dependent growth model that causes environmental pollution, (ii) waste and pollution imports from FDI inflows, and (iii) the division of international labor, Vietnam's low rank in the value chain accompanied by environmental pollution. The paper also provides policy implications for improving EPI in the context of economic integration, with particular emphasis on selecting growth model and how to recognize the value of environmental resources with economic development.
\end{abstract}

Keywords: Environmental performance index, economic growth, environmental protection, climate change, foreign direct investment, environmental management. 